\title{
Un retrato de la cultura local a través del Periodismo cultural. Análisis comparado de Sevilla y Porto Alegre
}

\author{
A portrait of the local culture through cultural Journalism. \\ Comparative analysis of Seville and Porto Alegre
}

\author{
Julieti-Sussi de Oliveira, Universidad de Sevilla. Av. Américo Vespucio s/n. C.P. \\ 41092, Sevilla, España. \\ julieti.oliveira@gmail.com | ORCID: https://orcid.org/0000-0003-4476-7791
}

DOI: https://dx.doi.org/10.12795/Ambitos.2020.i49.07

\begin{abstract}
Resumen
Las manifestaciones culturales son una parte fundamental en la formación de identidad y desarrollo social de los habitantes de una ciudad. Una cultura local bien identificada y fortalecida es necesaria para poner en valor las diferencias homogeneizadas por la globalización, los avances tecnológicos y la fuerte influencia del consumo. Para resaltar el valor la cultura local y lograr los objetivos de cohesión social, democracia cultural y participación en el espacio público que la misma conlleva, es necesario la colaboración del Periodismo y de su función como elemento cultural responsable de la retransmisión y la formación de gustos, el fomento y la recreación de manifestaciones culturales. La selección de la información a ser publicada en los periódicos plasma en sus secciones de cultura una panorámica de la cultura local que permite conocer la concepción de cultura que adoptan los medios. Eso nos ha permitido conocer qué espacio se da a la cultura local, así como conocer qué tratamiento se le atribuye. El Periodismo cultural local recoge los mismos patrones en sociedades tan alejadas geográficamente que se ve bastante influenciado por el mercado, por los grandes conglomerados de comunicación. Así, se fomenta una cultura de consumo reflejo de los movimientos de la gran industria cultural, regida a su vez por el ritmo que marca el consumo y casi olvidando la promoción, fomento y difusión del patrimonio y de la cultura local.
\end{abstract}




\begin{abstract}
Cultural manifestations are a crucial part in the identity formation and social development of the population of a city. A well-identified and strong local culture is fundamental to highlight the homogeneous differences resulting of globalization, technological advances and the strong influence of consumerism. In order to point out the value of the local culture and achieve its goals of social cohesion, cultural democracy and participation in the public sphere, it is necessary the intervention of Journalism and its function as a cultural element responsible for the retransmission and formation of liking, as well as the development and recreation of cultural manifestations. Selecting certain information to be publish on the cultural section of media shows a panoramic view of a local culture. This allows to know the conception of the culture adopted by the media. Cultural Journalism shows the same patterns in society as geographically distant but highly influenced by the market and worldwide communication groups. Thus, it is encouraged a culture of consumerism reflected by the cultural industry regulated by consumerism and almost forgetting the promotion, encouragement and dissemination of local patrimony and culture.
\end{abstract}

Palabras clave:Cultura, Periodismo, Industria cultural, Sevilla, Porto Alegre

Keywords: Culture, Journalism, Cultural industry, Seville, Porto Alegre

\title{
1. INTRODUCCIÓN
}

La globalización encierra cada vez más a las identidades locales por una cultura dispersa, de poca representatividad para los ciudadanos y mucho más pensada para el consumo. El desarrollo de los nuevos modos de vida urbano, la globalización, las nuevas tecnologías y la propia dinámica del mercado, decisiva en las estructuras de las nuevas formas de vida social, impone nuevas condiciones al producto cultural, alterando radicalmente la forma de entender la cultura. La economía aparece cada vez más ligada a la cultura a través del consumo, según Clanclini (1995), ya que el consumo de bienes materiales y medios de comunicación hoy es la respuesta para muchas de las inquietudes de los ciudadanos más que las reglas de la democracia o la participación en el espacio público. Este autor considera que el consumo interfiere en la formación de las identidades, pues los avances tecnológicos y los medios de comunicación repiensan la idea de unidad cultural, favoreciendo una homogeneización y una identidad mundial.

Por su parte, Keller (2012) piensa que vivimos en un tiempo en el que la valorización de lo local es clave para apreciar las diferencias apegadas a la globalización. La apuesta por la cultura local supone una distinción de lo global y una búsqueda de la identificación de los ciudadanos con sus ciudades. Así, en el contexto de la sociedad del siglo XXI, la cultura pasa a ganar protagonismo como factor de inclusión y desarrollo social en el cual la administración

Ámbitos. Revista Internacional de Comunicación | ISSN: 1139-1979 | E-ISSN: 1988-5733, №. 49. (2020) 
local se sitúa como principal fuente de construcción de una política cultural más cercana a los ciudadanos. Basta con observar que el gasto público de las administraciones locales ha sido un importante porcentaje en el cómputo global (Hernández y Rius-Ulldemolins, 2016).

Sin embargo, para que la cultura local llegue a los ciudadanos, la comunicación debe cumplir su función como retransmisora de la cultura para la formación de los gustos y los hábitos de consumo cultural (Bustamante y Lanas, 2016). De ese modo, la responsabilidad de los medios locales es extremadamente importante, específicamente el Periodismo Cultural, que destaca como una forma de cultura y que, en gran medida, difunde, fomenta y recrea las manifestaciones de la cultura.

El objetivo principal de esta investigación es trazar una panorámica de la representación de la cultura local a través del Periodismo cultural de los principales periódicos de dos importantes capitales nacionales Sevilla, España y Porto Alegre, Brasil.

\subsection{Métodos utilizados para el análisis}

Las ciencias sociales demandan hoy la proliferación de estudios de carácter inter o multidisciplinar que ayuden a un conocimiento global más completo. Nuestra investigación presenta un estudio comparativo basado en dos ciudades que ocupan un rol semejante en sus respectivos países y en la forma de gestionar la cultura desde la administración municipal, Porto Alegre (Brasil) y Sevilla (España).

Sevilla, capital de Andalucía, localizada al sur de España, cuenta desde 2006 con un organismo municipal, el Instituto de las Cultura y las Artes de Sevilla (ICAS), a través de cual se gestiona y se desarrollan las políticas culturales municipales aplicadas a los sectores.

A la vez, Porto Alegre, capital de Rio Grande del Sur, extremo sur de Brasil, deposita la gestión de la política cultural en la Secretaría Municipal del Cultural (SMC), órgano dependiente del ayuntamiento local que, desde 1988, es responsable del desarrollo de los sectores y agentes culturales de la ciudad.

Además, estas dos ciudades poseen características comunes que justifican un estudio comparativo como, por ejemplo, la gran diversidad cultural que influenciaron la formación y desarrollo de estas ciudades. En 2004, ambas firmaron la Agenda 21 de Cultura, un documento donde quedaba retratado el importante papel que asumían las ciudades en la gestión cultural. "La Agenda 21 de la cultura es el primer documento, con vocación mundial, que apuesta por establecer las bases de un compromiso de las ciudades y los gobiernos locales para el desarrollo cultural" (Agenda 21, 2004). 
En cuanto al Periodismo cultural, también se recogen similitudes que permiten un estudio comparativo, ya que, tanto en Sevilla como en Porto Alegre, los periódicos locales aún ejercen un rol importante como divulgadores de la vida cultural local. En ese sentido, este artículo presenta un panorama editorial de seis meses de los dos principales periódicos impresos de cada una de ellas. Así, en el caso brasileño, los diarios escogidos son Zero Hora, Correio do Povo, y en el caso español los diarios escogidos son Diario de Sevilla y $A B C$ de Sevilla.

Para el análisis, se ha seleccionado una muestra de seis meses, específicamente los seis primeros meses del 2018, considerando a cada edición diaria como unidades de muestreo. Sin embargo, teniendo en cuenta que son seis meses por cada periódico (180 días) y que son cuatro periódicos en total, el universo estadístico ascendería a 620 periódicos (ediciones diarias). Para acotar, se ha optado por seleccionar una muestra que fuera representativa del periodo basándonos en los cálculos muestrales proporcionados de Barranco Saiz (2010: 88). Así, se han seleccionado dos ediciones mensuales de cada periódico, sumando un total de 48 ediciones. A partir de ahí, nos hemos centrado en analizar todos los textos periodísticos de la sección de cultura, llegando a un total de 338 textos periodísticos analizados.

La intención de ese trabajo es realizar un análisis de cuño cuantitativo. En el análisis de contenido, se ha tenido en cuenta el número de veces que se hace referencia a la vida cultural local, ya sea a través de las actividades realizadas, la gestión de los espacios, la política cultural desarrollada por el ayuntamiento o ayudas establecidas. En definitiva, todas las manifestaciones culturales sucedidas en el espacio local y que fueran retratadas en la sección de cultura de los medios mencionados anteriormente.

Para realizar esto, se ha realizado una ficha de análisis con las siguientes categorías:

Referencia Espacial: identificar si los textos trataban hechos ocurridos en el ámbito internacional, nacional, regional o local. De ese modo, fue posible conocer cuántos de estos textos daban prioridad al ámbito local.

Referencia Temporal: a su vez, divididas en tres subcategorías:

- Novedad: cuando el texto se refiera a un acontecimiento novedoso, tratado por primera vez.

- Continuidad: cuando el texto vuelve a hablar de temas ya tratados anteriormente, ya sea dando una mayor profundidad al mismo o simplemente reforzando información.

- Efeméride: cuando el texto hace referencias a acontecimientos del pasado que se celebran ahora, como aniversario de fallecimientos o nacimientos de un autor o de una obra... 
Géneros periodísticos: hemos seguido las clasificaciones establecidas por los autores Rivera (1995), Tuñon (2000), Martínez Albertos (1999), Sánchez Callero (2011), Morrán Torres (1998).

Temáticas culturales: se ha buscado identificar cuáles son los temas culturales tratados en la sección de cultura.

\subsection{Una aproximación a los objetos de estudio $A B C$ de Sevilla}

El diario $A B C$ fue creado en Madrid en 1903, convirtiéndose rápidamente en el de mayor difusión nacional y, a la vez, el primer periódico español de difusión internacional. Su creadora, la familia Luca de Tena, gozaba de una posición acomodada, industrial y de tradición mercantil. Rodríguez y Torres (2007:256) definen ABC como "un periódico monárquico y conservador, aunque independiente de cualquier ideología política. El público de esta edición está en la aristocracia, la gran burguesía, la Iglesia y parte del Ejército; también en parte de la pequeña burguesía de provincias".

En 1929 se lleva a cabo la creación del $A B C$ de Sevilla, la que analizamos en esta investigación.

A lo largo de siglo XXI, el negocio familiar se fusionó con el Grupo Correo para dar lugar a VOCENTO, el único gran conglomerado mediático íntegramente de capital español.

\section{Diario de Sevilla}

En nacimiento de Diario de Sevilla en 1999 está relacionado con el éxito del Diario de Cádiz y el posterior desarrollo del grupo Joly. La iniciativa partió de Federico Joly, quien basó los principios del periódico en la no identificación política y en su fidelidad al público gaditano, cuyas "claves serán heredadas por la empresa que surja posteriormente y aplicadas como fórmula infalible de éxito en otras cabeceras" (Labio Bernal, 2011:341).

De acuerdo con Labio Bernal (2011), se buscaba alcanzar a los lectores que "no se identificaban ni con el $A B C$ de Sevilla ni con El Correo de Andalucía, y buscaban una información menos impregnada de matices ideológicos y llena de referencias locales". La experiencia de éxito con el Diario de Sevilla inspiró al grupo Joly a seguir expandiéndose por el territorio andaluz y, a día de hoy, es un importante grupo de comunicación en la comunidad autónoma.

\section{Zero Hora}

El diario nació en 1964 en Porto Alegre. En ese momento, la ciudad contaba con el diario Última Hora, inaugurado en 1960 y que formaba parte de la red nacional de diarios del periodista Samuel Wainer. Con la toma del poder político por los militares, el periódico fue 
cerrado. Es entonces cuando su director, Ary de Carvalho, asume la propiedad del mismo con la condición de cambiar su nombre. Así nace Zero Hora, posicionándose a favor del régimen militar instaurado.

Las inversiones necesarias para modernizar al diario llevaron a su dueño a una crisis financiera tal que le obligó a forjar una sociedad con el empresario de comunicación Mauricio de Sirotsky Sobrino. En 1970, la familia Sirotsky se hace con la totalidad de las acciones. Con su afiliación a la Rede Globo de Televisión, la inauguración de una red de transmisión de televisión y la compra de emisoras de radio y periódicos en diferentes ciudades motivaron el nacimiento del Grupo RBS, consolidado como la mayor empresa de comunicación del sur de Brasil. La hegemonía de los medios de comunicación del grupo establece su carácter de industria cultural (Fonseca, 2008).

\section{Correio do Povo}

Este diario fue creado en Porto Alegre en 1885 por Francisco Antônio Vieira Caldas Junior con la intención de crear un periódico moderno informativo y que estuviera alejado de las ideologías políticas.

Esa línea fue mantenida hasta 1924, cuando la dirección del periódico cambia de manos y el entonces director pasa a apoyar el nombre de Getulio Vargas para la presidencia de Brasil. A lo largo de los años, la empresa de la familia Caldas Junior fue aumentando sus negocios en los medios de comunicación. Además de los impresos, también adquirió emisoras de radio y televisión. Finalmente, en 2007, el medio pasó a formar parte de uno de los grandes conglomerados mediáticos brasileños, la Rede Record.

\subsection{Revisión teórica}

Para llegar a una aproximación sobre la relación cultura y comunicación, consideramos conveniente antes hacer una reflexión sobre la concepción de cultura, un término que admite diversas interpretaciones y que ha evolucionado a lo largo de la historia. Es por esto que Rodríguez Pastoriza (2006) aconseja analizarlo siempre en un momento histórico preciso, ya que la cultura se crea y se recrea a través de las diferentes relaciones sociales.

En cuanto a la relación cultura y comunicación, Rivera (1995) la relaciona directamente con el Periodismo a través de dos concepciones de cultura, una restringida al campo de las "bellas letras" y "bellas artes" y otra más amplia, a partir de la expansión de las perspectivas de la antropología cultural.

Después de la Segunda Gran Guerra, la producción cultural fue adquiriendo un carácter cada vez más mercadológico con el desarrollo y expansión de las industrias culturales, haciendo que la cultura quedara más relacionada con el consumo. Para Lipovetsky (2008), en la 
actualidad vivimos en la época de la hipermodernidad donde la cultura es un sector económico en plena expansión. En una sociedad de consumo donde la oferta de productos se hace cada vez mayor, el Periodismo cultural tiene el papel de poner orden, seleccionar aquello que merece ser consumido o no (Lipovetsky y Serroy, 2011).

En ese sentido, teniendo en cuenta la función del Periodismo como elemento cultural, Tuñon (2000:45) destaca los principales objetivos del Periodismo cultural: "promover el interés periodístico como forma de acrecentar la curiosidad por el conocimiento de la sociedad; ampliar y democratizar la cultura. La forma con la que el Periodismo cultural organiza y jerarquiza los contenidos que van a ser noticia marca la diferencia social y cultural del público, tanto por los contenidos con los que trabaja, como por las formas en la que se presentan, el tiempo, etc".

Antes de llegar al conocimiento del publico, los acontecimientos pasan por un proceso de selección operado por los profesionales de los medios. Según Gomis (1991), ese proceso está bajo influencia de diversos factores, entre ellos, el espacio disponible y el tiempo que la noticia llega a las manos del periodista. A estos factores hay que añadir la relación con las fuentes, con el público, factores éticos, históricos, políticos, económicos y sociales.

Uno de los modos de organizar y clasificar la información cultural es a través de los géneros periodísticos. "Los géneros periodísticos se pueden definir como los diferentes modos, estilos, códigos y convenciones que existen para ayudar al periodismo a interpretar la realidad social y aparecen vinculados a su propia historia (Sanchéz Callero, 2011:166).

De ese modo, el periodista consigue organizar la información elaborando textos que facilitan además el entendimiento al lector. Conocer los géneros permite también comprender el texto y ayudan a conocer la intención y la función de un medio de comunicación (Santamaría, 1994).

En la actualidad, con los cambios y transformaciones que están sufriendo los medios de comunicación, la clasificación de los géneros periodísticos sigue en constante evolución. La aparición de géneros híbridos dificulta la identificación de los mismo según las definiciones clásicas. De todos modos, en el Periodismo escrito, a pesar de percibirse la inferencia de la evolución en la clasificación de los géneros, mayormente se les puede identificar según las definiciones tradicionales. En ese sentido, salvo algunas pequeñas divergencias, autores como Rodríguez Vilamor (2000) o Morán Torres (1988) consideran que la clasificación más ajustada es la que se divide entre géneros informativos y de opinión. A su vez, Martínez Albertos (1992) añade los géneros interpretativos.

Dentro de cada una de esas clasificaciones, los géneros de dividen en distintas categorías que pueden ser encontradas en el Periodismo escrito, tales como, la noticia, el reportaje, la entrevista, la crónica, el artículo, la columna, la crítica, la reseña y las notas informativas. 


\section{RESULTADOS DEL ANÁLISIS}

Las informaciones obtenidas a través del análisis permiten inferir las tendencias de los periódicos durante los seis meses estudiados, enero a junio de 2018. Fueron registradas 48 ediciones, obteniendo un total de 338 textos analizados. En la secuencia se describirán los datos obtenidos a partir de la organización de los textos en categorías y subcategorías. Todo esto sin olvidar nuestro objetivo principal, que era conocer qué lugar ocupa la cultura local en los periódicos locales de dos ciudades, Sevilla (España) y Porto Alegre (Brasil).

\subsection{Referente espacial}

En primer lugar, se ha buscado conocer las referencias al ámbito local en la sección de cultura de cada medio para después centrarnos solamente en el análisis de los textos relacionados con la cultural local. Para ello, se ha divido la categoría Referente Espacial en cuatro subcategorías: local, regional, nacional e internacional.

En esta primera selección se pueden observar en la tabla abajo los datos encontrados.

Tabla 1

Resultado total de la referencia espacial en cada uno de los periódicos

\begin{tabular}{|l|c|c|c|c|}
\hline Referente Espacial & ABC de Sevilla & Diario de Sevilla & Correio do Povo & Zero Hora \\
\hline Local & 23 & 37 & 76 & 47 \\
\hline Regional & 0 & 8 & 2 & 6 \\
\hline Nacional & 23 & 18 & 12 & 16 \\
\hline Internacional & 10 & 21 & 24 & $\mathbf{8 7}$ \\
\hline Total & $\mathbf{5 3}$ & $\mathbf{8 4}$ & $\mathbf{1 1 4}$ & \\
\hline
\end{tabular}

Fuente: Elaboración propia a partir de datos de los periódicos (2020)

De modo general, los cuatros diarios analizados ofrecen un espacio mayor a la información cultural local, del total de 338 textos encontrados 183 de ellos hacen referencia al ámbito local, aunque es evidente el mayor espacio dedicado por los periódicos portoalegrenses (123 textos) frente a los sevillanos (60 textos). 
Gráfico 1

Análisis comparativo del total de referencia al ámbito local

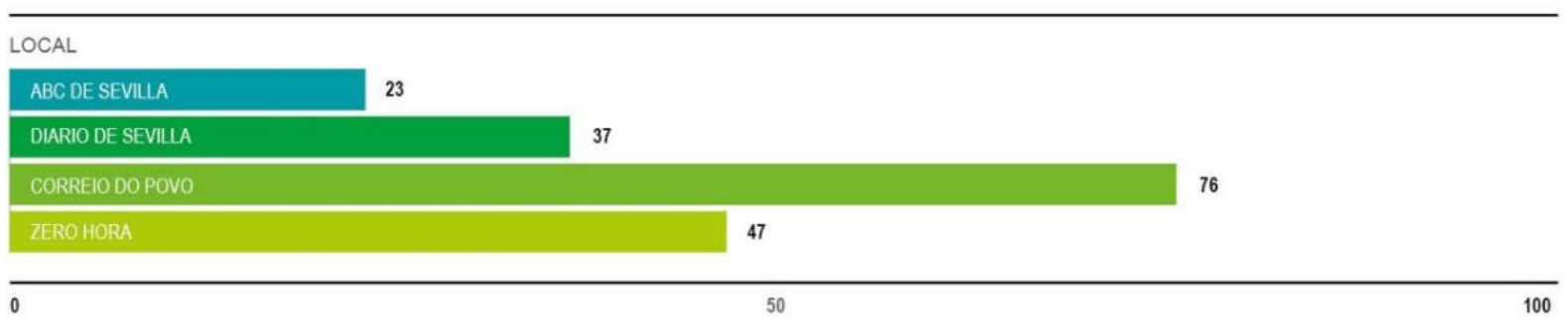

Fuente: Elaboración propia a partir de datos de los periódicos (2020)

Si contrastamos ese resultado con el número de páginas de la sección de cultura diaria de cada medio, consta que es Diario de Sevilla el que cuenta con más paginas, 5 entre semana y 10 en la edición de domingo.

Por su parte, $A B C$ de Sevilla destina solamente 3 páginas y en la edición de viernes, además de la sección cultural, incluye un cuaderno especial llamado $A B C$ de Ocio en el que cubre temáticas relacionadas con estrenos de cine, música, teatro, en la gran mayoría de las veces haciendo referencias al ámbito nacional o internacional, donde destina un gran espacio al género de la crítica. Se puede observar, de ese modo, la concepción de cultura que tiene el medio, pues en su sección de cultura denominada Cultura trata temáticas relacionadas con la pintura, los museos, exposiciones de arte, obras literarias y considera actividades culturales como cine, teatro, música, danza en un sentido más de ocio y diversión, dando a las mismas un espacio aparte y solo los viernes, como si fuera una especie de agenda para el fin de semana.

A su vez, el Correio do Povo es el que más textos periodísticos publica de modo general y, específicamente, en lo local. El diario divide la sección de cultura en dos momentos, de lunes a viernes con $A \& A$ (Arte \& Agenda, con 4 páginas diarias y un carácter más informativo, mientras que los sábados publica en el cuaderno especial Caderno de Sábado, con seis páginas y una edición formada por entrevistas, sección, reportajes y crónica cultural.

Diario de Sevilla y Zero Hora no diferencian entre las ediciones de entre semana y fin de semana, siguen manteniendo el mismo nombre, Cultura y Ocio (Diario de Sevilla), y Segundo Caderno (Zero Hora), aunque ambos medios dedican más espacio a la cultura durante el fin de semana. En concreto, Diario de Sevilla amplia la información cultural en la edición del domingo y Zero Hora en la del sábado, ya que este último periódico no tiene edición impresa dominical.

En cuanto a las referencias locales, llama la atención el caso del $A B C$ de Sevilla, el cual presenta el mismo número de referencias locales que nacionales. Esto puede explicarse si tenemos en cuenta el origen de ese medio, pues proviene de uno de los principales periódicos 
nacionales afincado en Madrid, donde se establecen sus principales redactores y su centro de informaciones.

Otro punto destacable en este análisis de referencias espaciales es referenciación a la región a la que pertenecen, ya que los cuatros medios están localizados en ciudades que tienen la condición de capital de su comunidad autónoma en el caso de Sevilla y del estado confederado en el caso de Porto Alegre. En ese sentido, Diario de Sevilla y Zero Hora son los medios que más representan el ámbito regional. Podemos identificar en los orígenes de estos medios la relación con el resultado presentado. Estos dos periódicos forman parte de grupos de comunicación con empresas en las diferentes ciudades de la región. En el caso específico de Zero Hora, el propio diario impreso en la capital es distribuido en las diferentes ciudades del estado de Rio Grande del Sur.

Finalmente, con ese primer acercamiento los 183 textos periodísticos relacionadas con la subcategoría local, serán analizados más en profundidad en la secuencia.

\subsubsection{Referente temporal}

Se observa que el periodismo cultural sigue la línea editorial del Periodismo diario, ya que la mayoría de las referencias al tiempo de las publicaciones están relacionados con la novedad, la actualidad.

La presencia de las efemérides o continuidad reflejan una condición básica de la narrativa periodística. Como efeméride se entiende un tiempo que, tras ser vuelto al pasado en un ritmo cíclico, concede una perspectiva histórica al espacio periodístico. Una construcción de la memoria social a través del homenaje a personajes, obras, autores, etc. Sin embargo, de modo general, en la cultura proyectada por los periódicos locales analizados, tales características alcanzan un espacio mínimo.

Tabla 2

Resultado total de la referencia temporal en cada uno de los periódicos

\begin{tabular}{|l|c|c|c|c|}
\hline Referente Temporal & ABC de Sevilla & Diario de Sevilla & Correio do Povo & Zero Hora \\
\hline Novedad & 17 & 24 & 69 & 38 \\
\hline Continuidad & 5 & 12 & 7 & 8 \\
\hline Efeméride & 1 & 1 & 0 & 1 \\
\hline Total & 23 & 37 & 76 & 47 \\
\hline
\end{tabular}

Fuente: Elaboración propia a partir de datos de los periódicos (2020) 


\subsubsection{Géneros periodísticos}

En este apartado se ha procedido a observar y contabilizar los géneros periodísticos encontrados en las páginas de cultura, lo que nos ayuda a conocer el perfil periodístico de cada medio. La noticia predomina en tres de los medios, con excepción de Correio do Povo, el cual prioriza las notas informativas. El reportaje y la entrevista también ocupan un puesto significativo dentro de los resultados. De este modo, queda claro el enfoque informativo adoptado por todos los medios, relacionados directamente con el referente temporal novedad, ya que la actualidad y novedad prevalecen en la información.

Los géneros analíticos como la crítica tienen menor presencia en todos los medios e incluso inexistente en el caso de Correio do Povo. Aquí destaca Diario de Sevilla, donde la crítica es el género con mayor presencia. En concreto, 13 de 37 textos son dedicados a la crítica cultural, principalmente de teatro, danza y música, escritas por críticos expertos en las diferentes temáticas tratadas. A eso se suma el hecho de que la edición de domingo es bastante amplia, llegando incluso a 10 páginas, con reportajes especiales, entrevistas, reseñas de libros... En comparativa con los demás medios analizados, se puede decir que el periódico sevillano ofrece una atención más profunda a la cultura local. Además de informar sobre actividades y acontecimientos culturales, busca formar opinión utilizando para ello la perspectiva de expertos en diferentes áreas culturales.

En la dirección contraria se encuentra el diario Correio do Povo, pues su perfil periodístico en relación a la cultura local está totalmente enfocado a la información. Tanto es así que la noticia y la nota informativa suman 68 textos de un total de 76 . El carácter informativo se puede observar claramente en el nombre de la sección de cultura del mismo A\& A (Arte \& Agenda), quedando clara su intención de informar sobre la programación cultural de la ciudad. No obstante, hay que recordar que en la edición del sábado la sección cambia de nombre y de perfil periodístico, pasando a ser el Caderno de Sábado. Además de contar con un mayor número de páginas, seis páginas concretamente, el cuaderno se dedica a una temática especifica cada sábado y presenta reportajes, columnas redactadas por expertos en literatura, historia, psicología, etc. También hay que decir que, durante el periodo analizado, no se han encontrado referencias a la cultura local en esa edición.

En $A B C$ de Sevilla, así como en Zero Hora predominan mayormente los géneros informativos, la noticia, la nota informativa, el reportaje. Como se ilustra en la tabla abajo. 
Tabla 3

Resultado total de los géneros periodísticos en cada uno de los periódicos

\begin{tabular}{|l|c|c|c|c|}
\hline Géneros & ABC de Sevilla & Diario de Sevilla & Correio do Povo & Zero Hora \\
\hline Noticia & 8 & 9 & 19 & 26 \\
\hline Reportaje & 6 & 10 & 6 & 4 \\
\hline Columna & 1 & 0 & 7 & 2 \\
\hline Entrevista & 1 & 3 & 0 & 3 \\
\hline Critica & 1 & 13 & 0 & 2 \\
\hline Crónica & 3 & 1 & 15 & 10 \\
\hline Notas Breves & 3 & 1 & 29 & 47 \\
\hline Total & 23 & 37 & 76 & 4 \\
\hline
\end{tabular}

Fuente: Elaboración propia a partir de datos de los periódicos (2020)

\subsubsection{Temáticas}

La variedad temática abarca 19 temáticas registradas que van desde las más tradicionales, como música, teatro, artes visuales o libros, hasta temas diversos como tecnologías, artes digitales o gastronomía. También se han encontrado temáticas de política y gestión cultural, muy interesantes para esta investigación. Todo ello indica el eclecticismo y la perspectiva cultural amplia de los periódicos analizados. Aún con toda esta variedad, las temáticas que más veces se han encontrado en los cuatro medios analizados son música, teatro, cine y libros, algo que los sitúa en una concepción más estricta de cultura, relacionada especialmente con el circuito comercial, con los eventos y con la oferta de productos.

Si nos centramos en la categoría música, se puede inferir que el movimiento del mercado de las productoras musicales constituye uno de los pilares de la sección de cultura. Tanto es así que esta temática está relacionada con 50 de los 138 textos. Si observamos qué tipo de tratamiento recibe esta temática, se concluye que los géneros informativos predominan. Se destacan la realización de conciertos, presentación de nuevos discos, presencia de algún sujeto notorio del mundo musical, siempre guiados principalmente por la novedad y la actualidad.

También el teatro recibe un espacio destacado dentro de las secciones de cultura, con 58 textos. Así como la música, esa temática está relacionada con la producción cultural y con el evento. Sin embargo, se observa que la presencia del teatro es bastante mayor en los periódicos de Porto Alegre, sumando 44 menciones. Este protagonismo se puede justificar por la gran presencia que el teatro tiene en la ciudad brasileña, famosa por realizar grandes eventos, como el Festival de Teatro Porto Verão Alegre, organizado anualmente entre enero y febrero. También hay que recordar que la ciudad organiza uno de los principales festivales de teatro del país, Poa em Cena, pero no entra en este análisis porque acontece anualmente en el mes de octubre, saliéndose de nuestro periodo de análisis. 
La óptica más tratada en este caso es predominantemente informativa, pero también analítica, especialmente en el Diario de Sevilla, donde más crítica de teatro se ha encontrado (13 unidades de análisis).

La siguiente temática con mayor presencia en los cuatro medios es el arte visual, relacionada principalmente con exposiciones de arte, pintura, fotografía y escultura. Esta está relacionada con programación cultural de la ciudad, al ritmo de la novedad, pero también de la efeméride y del evento. Hay que señalar que, en el caso de Sevilla, durante todo el año 2018, se celebró el IV Centenario de Murillo, unos de los nombres más importantes de la pintura, aun así, esta temática ocupa en la prensa sevillana la misma posición que en los diarios de Porto Alegre, de lo que se deduce que tal evento no ha tenido gran impacto en la prensa de Sevilla, o que el campo de artes visuales no cuenta con gran movimiento en la ciudad.

El cine y el libro también están dentro de las temáticas más tratadas, aunque en menor cantidad. De igual modo que las temáticas anteriores, estas están conectadas con la novedad, con el mercado editorial o la industria del cine, estrenos de películas y presentación de libros. Están marcadas principalmente por el carácter informativo, sobre todo por las notas informativas y entrevistas a algún autor local publicadas. En el caso del cine y del libro, se comprende que es una industria con una mayor fuerza está del mercado internacional y nacional. El papel de las ciudades en este caso está definido por la organización de festivales, ferias del libro, la manutención de bibliotecas municipales o la presencia de salas de cine municipal. En el caso del cine, se justifica la mayor presencia de esta temática en los dos periódicos de Porto Alegre, 16 textos frente a los 2 de Sevilla, ya que la ciudad brasileña cuenta con una importante sala municipal de cine donde, además de exhibición de películas, organiza exposiciones, charlas, debates y eventos con las escuelas del municipio.

Finalmente, después de haber observado la fuerte presencia de los eventos en la cultura local, nos parece importante señalar aquí que ambas ciudades se pueden encontrar importantes festivales que fomentan la cultural local, como la Bienal de Flamenco, El Festival de Cine, el Poa em Cena o la Feria del Libro. En ese sentido, se debe tener en cuenta que el periodo de análisis de esta investigación comprende el primer semestre del año y que, en ambas ciudades, los eventos señalados ocurren en el segundo semestre. Basado en cómo se comportan los medios y las líneas que siguen, se deduce que, si incluyéramos esa acotación temporal dentro del análisis, la presencia de la cultura local en la prensa sería mayor, sobre todo porque se trata de eventos muy destacados en el mercado y que atrae un impacto económico considerable.

Por último, la principal diferencia encontrada en esta categoría se da en la variedad de temas. Así, se observa que los dos periódicos portoalegrenses incluyen temáticas más alejadas del concepto tradicional de cultura, como industrias creativas, artes digitales o gastronomía. También llama la atención las referencias a la política cultural local que se observan en Correio do Povo, pues en ocho de los textos se han localizado referencias a la actuación de la administración local en el sector cultural de Porto Alegre. 
Tabla 4

Resultado total de las temáticas en cada uno de los periódicos

\begin{tabular}{|l|c|c|c|c|}
\hline Temáticas & ABC de Sevilla & Diario de Sevilla & Correio do Povo & Zero Hora \\
\hline Música & 8 & 13 & 28 & 10 \\
\hline Teatro & 5 & 9 & 21 & 23 \\
\hline Artes Visuales & 3 & 7 & 17 & 1 \\
\hline Flamenco & 1 & 1 & 0 & 0 \\
\hline Historia & 1 & 2 & 0 & 2 \\
\hline Danza & 1 & 1 & 8 & 0 \\
\hline Libros y Literatura & 3 & 4 & 0 & 2 \\
\hline Gestión Cultural & 1 & 2 & 7 & 2 \\
\hline Cinema & 0 & 2 & 8 & 1 \\
\hline Political Cultural & 0 & 1 & 0 & 0 \\
\hline Gastronomia & 0 & 0 & 0 & 0 \\
\hline Patrimonio & 0 & 3 & 1 & 5 \\
\hline Medios de Comunicación & 0 & 1 & 1 & 0 \\
\hline Artes Digitales & 0 & 0 & 1 & 0 \\
\hline Artesanía & 0 & 0 & 0 & 1 \\
\hline Circo & 0 & 0 & 0 & 2 \\
\hline Poesia & 0 & 0 & 0 & 1 \\
\hline Carnaval & 0 & 0 & 0 \\
\hline Industrias Creativas & 0 & 0 & 0 \\
\hline
\end{tabular}

Fuente: Elaboración propia a partir de datos de los periódicos (2020)

\section{CONCLUSIONES}

Se puede decir que, a pesar de las diferencias sociales de las ciudades a las que pertenecen los cuatro diarios analizados, el Periodismo cultural adopta unas características comunes en ellos. Estos medios no están muy preocupados en difundir una cultura local democrática, plural. Más bien, lejos de ofrecer una representación e identificación cultural a nivel local, los medios de comunicación se centran principalmente en sus secciones de cultura siguiendo y fortaleciendo la cultura de consumo. Prueba de ello es que las temáticas más tratadas sean la música y el teatro, siguiendo una lógica comercial de acuerdo con los intereses del mercado. Temáticas como bibliotecas municipales o espacios municipales como museos, actividades de grupos de teatro, títeres o exposiciones están muy poco representadas en las páginas de cultura de los diarios analizados.

La narrativa de los medios describe fragmentos de la cultura local, regida por los ciclos del evento y por el marco temporal de novedad. A pesar de la amplitud de temáticas que tiene la cultura, las productoras musicales y teatrales son para el mercado un eje fundamental en la creación de pautas, sin tener en cuenta los objetivos de cohesión social, promoción, distribución y difusión del patrimonio y de la cultura local. 
En el caso de Zero Hora, Correio do Povo y $A B C$ de Sevilla, su posición como integrantes de grupos de comunicación, que incluso son grandes conglomerados de comunicación, como el Grupo RBS o la Rede Record en Porto Alegre, repercute en que en sus páginas reservan un espacio bastante considerable a actividades culturales realizadas o financiadas por el propio grupo.

Los datos obtenidos aquí permiten hacer una panorámica para problematizar cómo el Periodismo cultural, productor de sentidos para la interpretación de la cultura y la memoria local, construye una representación de la ciudad como agente de la esfera cultural, espacio de capital simbólico y creativo. En un futuro trabajo entraremos en una etapa cualitativa con una muestra más amplia donde se buscará identificar los agentes, los territorios representados y las estancias, trazando una perspectiva del paisaje cultural de la ciudad construida por los medios de comunicación.

\section{Referencias}

Agenda 21 de la cultura (2004). IV Fórum de Autoridades Locais de Porto Alegre (FAL). Recuperado de http://www.agenda21culture.net/es

Barranco Saiz, F. J. (2010). Marketing Político y Electoral. Madrid. Piramide.

Bustamante, H.; Lanas C., P., (2016). Políticas de la comunicación y la cultura en España. Balance de una articulación siempre precaria. In. (Rius-Ulldemolins, Joaquim, Rubio Arostegui, J. A.) Treinta años de política cultural en España. Participación cultural, gobernanza territorial e industrias culturales. Universitat de Valencia.

Canclini, N. G. (1995). Consumidores e cidadãos: conflitos multiculturais da globalização. Rio de Janeiro, UFRJ.

Fonseca, V. P. (2008). Indústria de notícias: capitalismo e novas tecnologias no jornalismo contemporâneo. Porto Alegre: UFRGS.

Gomis, L. (1991). Teoría del Periodismo: cómo se forma el presente. Barcelona. Paidós.

Hernàndez, M. G., Rius-Ulldemolins, J. (2016). La política cultural en las grandes ciudades. Giro emprendedor, globalización y espectacularización de la modernidad avanzada. In. (RiusUlldemolins, J., Rubio Arostegui, J.,A) Treinta años de política cultural en España. Participación cultural, gobernanza territorial e industrias culturales. Universitat de Valencia.

Keller , S. (2012). Um mapa da vida cultural no Rio Grande do Sul: análise do caderno Cultura (2010). Diss. (Mestr. em Comunicação e Informação) Porto Alegre, UFRGS.

Labio B., A. (2011). "Estructura informativa a comienzos de siglo XXI". In: La comunicación en Andalucía: historia, estructura y nuevas tecnologías (orgs.) Ramón Reig, Concha Langa. Sevilla. Centro de Estudios Andaluces. 
Lipovetsky G. Charles S. (2004). Os tempos hipermodernos. São Paulo. Barcelona.

Lipovetsky G. Serroy, J. (2011). A cultura-mundo: resposta a uma sociedade desorientada. São Paulo. Companhia das Letras.

Martinez Albertos, J., L. (1999). "El Periodismo en el siglo XXI. Más allá del rumor y por encima del caos" en Estudios sobre el mensaje periodístico, n. 5 (Departamento de Periodismo I, Universidad Complutense) Madrid.

Morán Torres, E. (1988). Géneros del periodismo de opinión. Crítica, comentario, columna, editorial. EUNSA, Pamplona 1988, 237 pp.". Communication and Society. 1 (1), 1988. Disponible en hdl.handle.net/10171/57255

Rivera, J. (1995). El periodismo cultural. Buenos Aires. Paidós.

Rodríguez, A., Torres T. M. (2007). Los Luca de Tena. La primera familia periodística de España. In. Checa Godoy A. Espejo Cala. C. Ruiz Acosta. M.J. (coord.) ABC de Sevilla, un diario y una ciudad. Análisis de un modelo de periodismo local. Universidad de Sevilla.

Rodríguez Pastoriza, F. (2006) Periodismo cultural. Madrid: Síntesis.

Rodríguez Vilamor, J. (2000). Redacción periodística para la generación digital. Madrid. Universitas.

Sánchez Calero, M. L. (2011). Géneros y discursos periodísticos. Ed. Fragua. Madrid.

Santamaría S. (2000). La Opinión Periodística: argumentos y géneros para la persuasión. Madrid. Fragua Editorial.

Tuñón, A. (2000) Periodismo especializado y cultura de la información. Barcelona: en Universitat i Periodisme, Universidad Autónoma de Barcelona. 